\title{
陳旧性心筋梗塞に合併する致死性不整脈への挑戦
}

\section{Progress in Treatment of the Lethal Ventricular Arrhythmia in Patients with Old Myocardial Infarction}

合屋雅彦

1980 年代には CCUの導入により心筋梗塞の急性期の生命予後が改善され, そ の後, 心筋梗塞の亜急性期から遠隔期に生じる致死性不整脈による突然死が問題と なつた. 80 年代後半に行われた抗不整脈薬による一次予防試験により, 抗不整脈 薬の予防投与は無効であるのみならず，生命予後をむしろ悪化させることが明らか となり，2000年代初頭にICDの予防的留置が有効であることが報告された。しか しながらICDの作動例, 特に storm群の予後が悪く, 加えて予防的留置を行つた 症例での 21 力月間の作動率は約 4 分の 1 と低く, 予防的留置が必要な症例の選別 が必要であることも併せて明らかとなつた，一方，カテーテルアブレーションは 3 次元マッピングシステムとそれによる substrateマッピング, 心外膜側アプローチ の導入などによりその成績は飛躍的に改善している．陳旧性心筋梗塞に合併する致 死性心室不整脈の領域において, 現在予防的 ICD留置を真に必要とする群の選別, 1 次予防としてのカテーテルアブレーションの有用性の検討, 抗不整脈とのハイブ リッド療法などが課題である.

\section{I. 序 文}

急性心筋梗塞は致死率の高い疾患であったが, CCUの導入により生命予後が改善された. しかし， 心筋梗塞亜急性期から遠隔期において突然死をきた す症例が問題となった８0年代後半には，まず抗 不整脈薬による突然死予防が試みられたが, 無効で あった。次に導入されたのが植达み型除細動器 (ICD)である。しかし，ICD留置は低左心機能症例 の突然死予防に有用であったが，真に必要な症例の 選別が難しいこと, 頻回作動例の死亡率が高いこと などの問題が明らかとなった。その次にカテーテル
アブレーションが導入された．カテーテルアブレー ションは，3次元マッピングシステムの導入により 致死性心室不整脈の治療においても進歩を遂げてい る. 心内膜側のみならず心外膜側のアブレーション も行われるようになり，さらにエコー， CT, MRI などとの組み合わせによる病変の 3 次元明瞭化, 1 次予防への導入が試みられている。しかし残された 課題も多い.

このように，陳旧性心筋梗塞に合併する致死性心 室不整脈に対する治療手段は，現在のところ抗不整 脈薬, 植达み型除細動器 (ICD), カテーテルアブ レーションの 3 つである。本稿では前 2 者について

小倉記念病院循環器内科（干 802-8555 福岡県北九州市小倉北区浅野 3-2-1)

Masahiko Goya

• Key words ; 陳旧性心筋梗塞, 心室頻拍, カテーテルアブレーション 


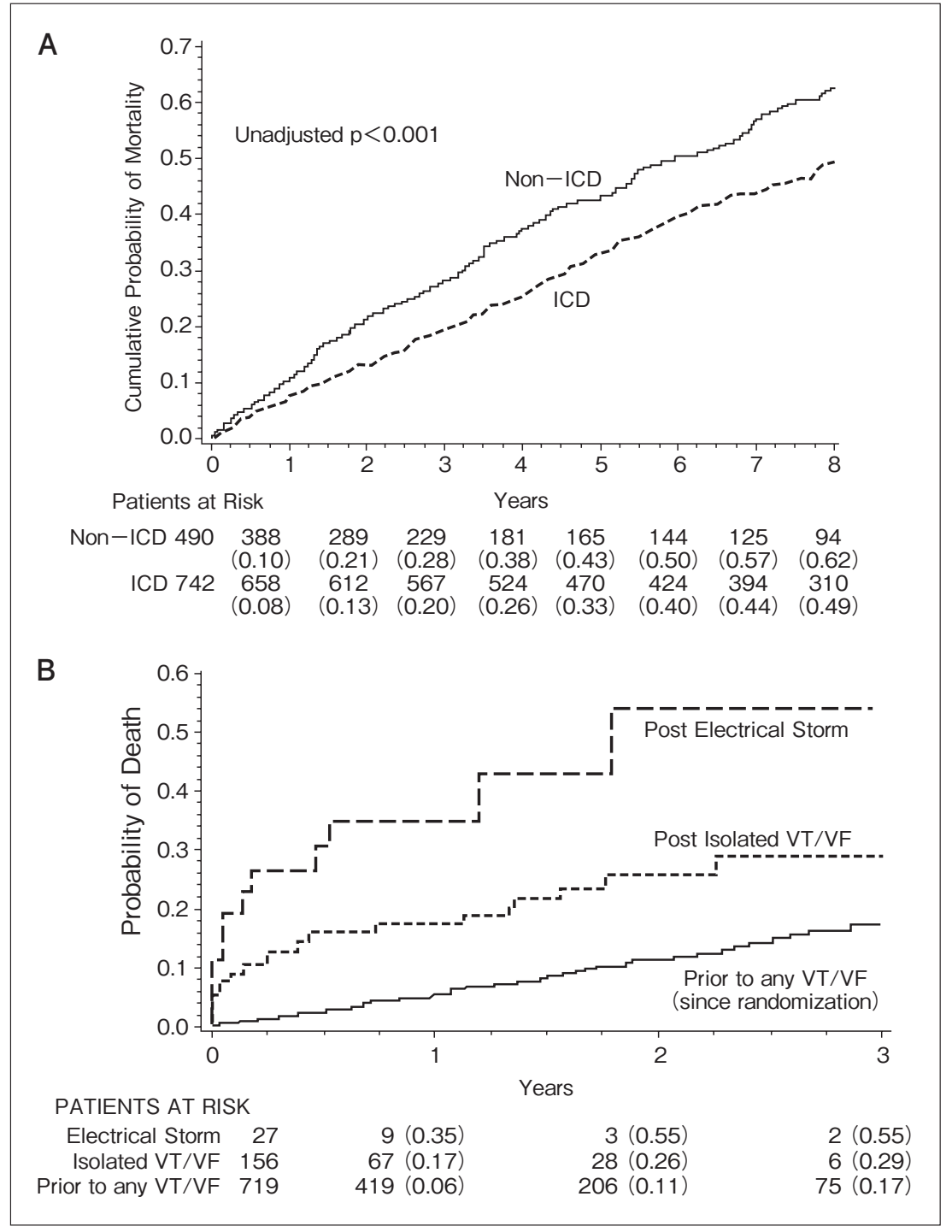

図 1

A : MADIT- II 研究の長期成績

〔文献 4)より引用改変〕

B：MADIT- II 研究に掞けるICD作動な

し群, stormなし群, storm群の予後

〔文献 5)より引用改変〕

は簡単にふれることとし，主にカテーテルアブレー ションにつき概説したい.

\section{II. 抗不整脈薬}

1970年から 80 年にかけて, 心筋梗塞後の突然死 症例にはハイリスクな心室期外収縮の多発が認めら れることが報告された。そこで心室期外収縮を Ic 群の抗不整脈薬を用いることにより抑制し，生命予 後を改善できるのではないかと期待され，CAST研 究 ${ }^{1)}$ がなされた。しかし，期待に反して Ic 群抗不 整脈薬の予防投与は, 生命予後をむしろ悪化させる ことが明らかとなった。この結果から, 致死性心室
不整脈に対する抗不整脈薬の予防投与 (1 次予防) は 不適当であり，抗不整脈薬は 2 次予防のみに用いら れることとなった。

\section{III. 植込み型除細動器 (ICD)}

2002年に報告された MADIT- II 研究 ${ }^{2)} に よ り ，$ 低左心機能 (左室駆出率 $30 \%$ 未満) の陳旧性心筋梗 塞症例に対しては心室不整脈の有無にかかわらず, ICDの予防的留置により生命予後を改善することが

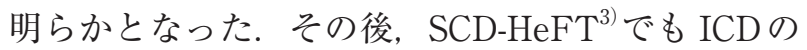
予防的留置の有効性が証明されたため, ICD留置の 症例数は飛躍的に増大した。 
ICDの予防的留置は生命予後の改善に寄与したも のの, いくつかの課題も明らかとなった．2010年 に報告された MADIT- II 研究の長期観察結果 ${ }^{4)}$ は, 留置後平均 21 力月までの適正作動率は $23.5 \%$ にすぎず, 留置後 2 年以降の死亡の増加率は ICD 留置例と非留置例でほぼ同等であった(図 1A)。こ れは ICDの予防的留置を必要とする症例が, 非常 に限られることを示唆している。また, Sesselberg ら ${ }^{5)}$ は, やはり MADIT- II 研究の患者群を用いて, ICDの予防的留置を行った症例において適正作動が 1 回以上認められる症例群は認められない症例群よ り予後が悪いこと, 特に electrical stormを生じる と hazard ratioが 7.5 と非常に高くなることを報告 した(図 1B)。これらは，ICDの予防的留置は生命 予後の改善に寄与するものの, ICD 単独治療では限 界があることを示唆している。

\section{IV. カテーテルアブレーション}

陳旧性心筋梗塞に合併する心室頻拍 (VT)に関し ては, El-Sherif らが興奮旋回路の模式図としての 8 字模型を提唱した。1990年には, de Bakkerらが心 筋梗塞巣内の傷害心筋が channelを形成し，この channelがマクロリエントリー回路の峡部となりう ることを病理標本を用いて証明した。 その後, 1993 年にStevenson ${ }^{6)}$ が頻拍のリエントリー回路のモ デルを提唱し, 通電の標的となるリエントリー回路 上の遅延伝導部位の電気生理学的特徵を明らかにし た. 2000年頃から，各種難治性不整脈に対するア

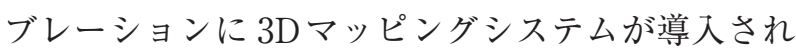
た. OMI - VTのアブレーションにおいても, 3D マッピングシステムにより頻拍基質の 3 次元的な理 解が可能になり，従来は血行動態が不安定あるいは 頻拍が誘発不能であるために頻拍中のマッピング (VT mapping) が不可能とされた症例に対しても, 洞調律中のマッピング(substrate mapping)による アブレーションが可能となったことで, アブレー ションの有用性が向上した. 2001 年に, Soejima ら ${ }^{7)}$ がCARTO システムを用いて同定した低電位領域
(LVA) 辺縁のペースマップが良好な部位から, 内 部へ線状にアブレーションを行うことにより頻拍の 焼灼に成功したと報告した. 2002 年には, Soejima $ら^{8)}$ が LVA内で洞調律下に高出力ペーシングを 行っても捕捉の得られない部位を EUS (electrically unexcitable scar) とし, 緩徐伝導部位は EUSの近 傍に存在することを明らかにした。一方 Arenal ら ${ }^{9)}$ は, LVA内で洞調律時および心室ペーシング時に 遅延電位 $(\mathrm{DP})$ が記録される部位が, 至適アブレー ション部位であるとした. 2004年には, Brunckhorst $ら^{10)}$ が梗塞巣内でのペースマッピングで channelが 同定可能であることを報告し, Bogun ら ${ }^{11)}$ の施設 からは洞調律時に記録される DP とペースマッピン グを組み合わせたアブレーションの有効性が報告さ れた。

われわれの施設では，以下のごとくアブレーショ ンを施行する. (1)洞調律下あるいは心室ペーシング 下にマッピングを行う。 (2) LVA (1.5 mV 以下)を認 める場合は LVA内を詳細にマッピングし, DPが 記録される部位を検索する. (3) DPを認める場合に は同部位においてペースマップを行い，標的となる VT 波形と比較検討する。良好なペースマップ波形 が得られた場合には周囲のペースマッピングを行 い, 刺激-QRS 時間から緩徐伝導部位の入口, 出口 部位を推定する. (4) DP 記録部位にカテーテルを固 定したままVTの誘発を試み, 洞調律時の DPが VT 時に拡張期電位に移行し, かつ Stevenson ら ${ }^{6)}$ の定義を満たす場合には高周波通電を行う。(5) DP が記録されない場合にはLVAの辺縁部において ペースマッピングし, マップが良好な部位(緩徐伝 導路からの出口部位)で高周波通電を行う.

またわれわれは図2に示すごとく, substrate マッピングを行う際には voltageを見るとともに， 局所のDPに annotationを行う delayed potential mapを作成している，この方法は，LVAが広範に 存在する場合（図 2A）にペースマッピングを行うべ き領域を限定し, 手技の効率を高めるのに有効であ る(図 2B・C)。また最近では, CARTOsoundを用 


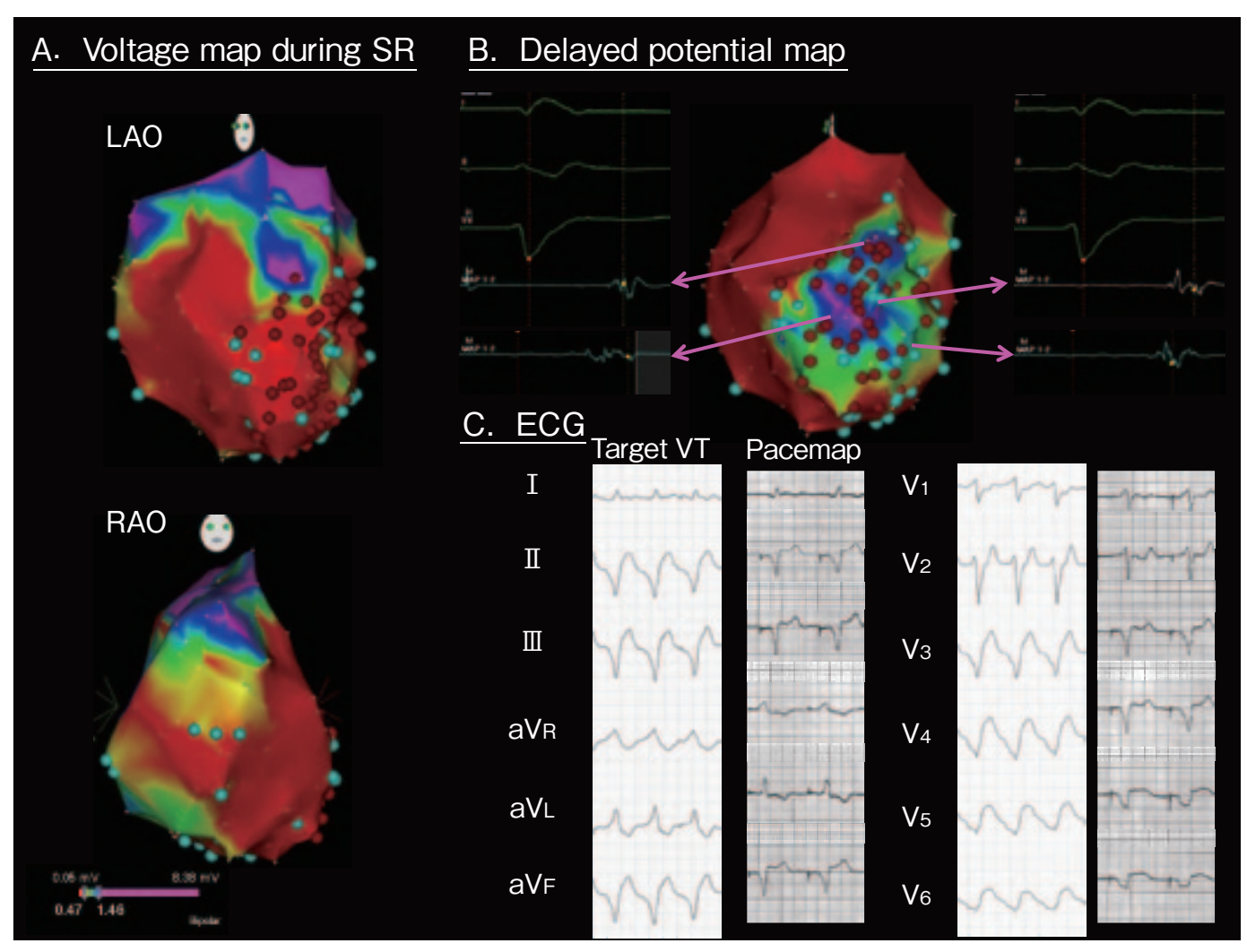

図 2 広範囲前壁心筋梗塞症例における delayed potential map
A : 左前下行枝, 回旋枝同時梗塞症例における洞調律時 voltage map.
B : Delayed potential map : delayed potentialに annotateすることにより, 遅延電位記録領域を明瞭 化することが可能である.
C : 遅延電位記録部位辺縁での pacemap は, 標的である心室頻拍と良好に一致している.

いたLVAの視覚化(図 3A), CT との MERGEによ る 3 次元イメージ化(図 3B)を行っている.

アブレーションのエンドポイントは, 従来すべて のVTあるいは発作時に認められたVTが誘発不能 となることとされていた。 しかし, Vergaraら ${ }^{12)}$ は すべての DPが消失することをエンドポイントとし た．その結果， $20 \%$ 症例で再発を認めたものの, DP 消失群ではVTの再発率は $9.5 \%$ であったが, DP 非消失群での再発率は $75 \%$ であり, DP消失を エンドポイントとするアブレーションは有用で, DP 消失の有無が再発の予測因子になりうると報告 している. その後, Jaïs ${ }^{13)}$ も同様の報告をしてお り, 今後は頻拍誘発不能性よりも DP消失を目標と するアブレーションが普及していくと考えられる.
2012 年のカテーテルアブレーションの適応と手 技に関するガイドラインでは, 器質的心疾患に合併 する持続型 VTに対するアブレーションの class 1 適応は，(1)心機能低下または心不全に伴う単形性持 続性 VTで, 薬物治療が無効または副作用のため使 用不能な場合, (2) ICDの植込み後に抗頻拍治療が 頻回に作動し, 薬物治療が無効または副作用のため 使用不能な場合, (3)単形性 VTが原因で心臟再同期 療法の両室ペーシング率が低下して十分な効果が得 られず, 薬物治療が無効または副作用のため使用不 能な場合，の3つをあげている．このガイドライン は, VTに対するアブレーションが, 現時点では ICD, 抗不整脈薬でコントロールができない場合の 追加療法であることを示唆している. しかしなが 


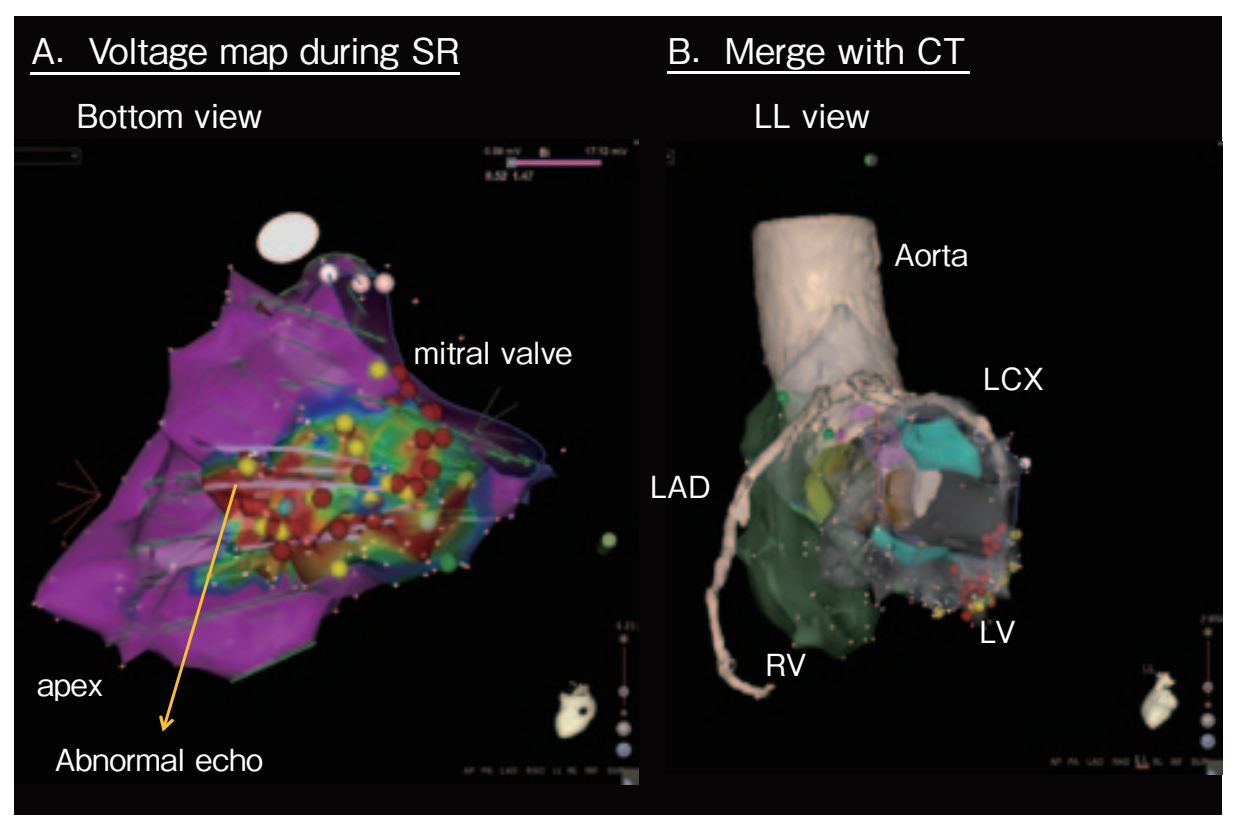

図 3 陳旧性下壁心筋梗塞症例における洞調律時 voltage map (bottom view) (A) およびCT との MERGE像 (B)

$\mathrm{A}$ ：エコーに扔ける梗塞部位(図中紫線) と異常低電位領域 ( $1.5 \mathrm{mV}$ 以下)が一致している.

$\mathrm{B} ：$ アブレーション部位(赤いポイント)の 3 次元位置, 特に冠動脈との位置関倸が明瞭で ある.

ら, SMASH-VT研究 ${ }^{14)}$, VTACH研究 ${ }^{15)}$ では, 陳 旧性心筋梗塞症例における予防的アブレーション が，心室不整脈の出現を抑制し，その結果 ICDの 作動を減少させうると報告している.

また近年，不整脈原性右室異形成に合併する VT に対し，心内膜側のみならず心外膜側にアブレー ションを行うと，治療成績を向上させうることが報 告 ${ }^{16)}$ された。陳旧性心筋梗塞に合併する致死性心 室不整脈に対しても，アブレーションの成績を向上 させるとともに，真に ICD留置が必要な症例の選 別，1次予防としてのアブレーションの有用性の検 討，抗不整脈薬とのハイブリッド治療など，今後さ らに解明，前進を続けていかなければならない領域 は多い.

\section{〔文献〕}

1 ) Echt DS, Liebson PR, Mitchell LB, Peters RW, ObiasManno D, Barker AH, Arensberg D, Baker A, Friedman L, Greene HL, Huther ML, Richardson DW, the CAST Investigators : Mortality and morbidity in patients receiving encainide, flecainide, or placebo. The Cardiac Arrhythmia Suppression Trial. N Engl J Med, $1991 ; 324: 781 \sim 788$

2 ) Moss AJ, Zareba W, Hall WJ, Klein H, Wilber DJ, Cannom DS, Daubert JP, Higgins SL, Brown MW, Andrews ML; Multicenter Automatic Defibrillator Implantation Trial II Investigators : Prophylactic implantation of a defibrillation in patients with myocardial infarction and reduced ejection fraction. $\mathrm{N}$ Engl J Med, $2002 ; 346$ : 877 883

3 ) Bardy GH, Lee KL, Mark DB, Poole JE, Packer DL, Boineau R, Domanski M, Troutman C, Anderson J, Johnson G, McNulty SE, Clapp-Channing N, DavidsonRay LD, Fraulo ES, Fishbein DP, Luceri RM, Ip JH ; Sudden Cardiac Death in Heart Failure Trial (SCDHeFT) Investigators : Amiodarone or an implantable cardioverter-defibrillator for congestive heart failure. N Engl J Med, 2005 ; 352 : 225 237 
4 ) Goldenberg I, Gillespie J, Moss AJ, Hall WJ, Klein H, McNitt S, Brown MW, Cygankiewicz I, Zareba W ; Executive Committee of the Multicenter Automatic Defibrillator Implantation Trial II : Long-term benefit of primary prevention with an implantable cardioverter-defibrillator : an extended 8-year followup study of the Multicenter Automatic Defibrillator Implantation Trial II . Circulation, $2010 ; 122$ : $1265 \sim 1271$

5 ) Sesselberg HW, Moss AJ, McNitt S, Zareba W, Daubert JP, Andrews ML, Hall WJ, McClinitic B, Huang DT ; MADIT- II Research Group : Ventricular arrhythmia storms in postinfarction patients with implantable defibrillators for primary prevention indications : a MADIT- II substudy. Heart Rhythm, $2007 ; 4: 1395 \sim 1402$

6 ) Stevenson WG, Khan H, Sager P, Saxon LA, Middlekauff HR, Natterson PD, Wiener I : Identification of reentry circuit during catheter mapping and radiofrequency ablation of ventricular tachycardia late after myocardilal infarction. Circulation, $1993 ; 88: 1647 \sim 1670$

7 ) Soejima K, Suzuki M, Maisel WH, Brunckhorst CB, Delacretaz E, Blier L, Tung S, Khan H, Stevenson WG : Catheter ablation in patients with multiple and unstable ventricular tachycardias after myocardial infarction : short ablation lines guided by reentry circuit isthmuses and sinus rhythm mapping. Circulation, $2001 ; 104: 664 \sim 669$

8 ) Soejima K, Stevenson WG, Maisel WH, Sapp JL, Epstein LM : Electrically unexcitable scar mapping based on pacing threshold for identification of the reentry circuit isthmus : feasibility for guiding ventricular tachycardia ablation. Circulation, 2002 ; 106 : $1678 \sim 1683$

9 ) Arenal A, Glez-Torrecilla E, Ortiz M, Villacastín J, Fdez-Portales J, Sousa E, del Castillo S, Perez de Isla L, Jimenez J, Almendral J : Ablation of electrograms with an isolated, delayed component as treatment of unmappable monomorphic ventricular tachycardias in patients with structural heart disease. J Am Coll Cardiol, $2003 ; 41: 81 \sim 92$

10) Brunckhorst CB, Delacretaz ED, Soejima K, Maisel WH, Freidman PL, Stevenson WG : Identification of the ventricular tachycardia isthmus after infarction by pace mapping. Circulation, $2004 ; 110: 652 \sim 659$

11) Bogun F, Good E, Reich S, Elmouchi D, Igic P, Lemola K, Tschopp D, Jongnarangsin K, Oral H, Chugh A, Pelosi F, Morady F : Isolated potentials during sinus rhythm and pace-mapping within scars as guides for ablation of post-infarction ventricular tachycardia. J Am Coll Cardiol, 2006 ; 47 : 2013 2019

12) Vergara P, Trevisi N, Ricco A, Petracca F, Baratto F, Cireddu M, Bisceglia C, Maccabelli G, Della Bella P : Late potentials abolition as an additional technique for reduction of arrhythmia recurrence in scar related ventricular tachycardia ablation. J Cardiovasc Electrophysiol, $2012 ; 23: 621 \sim 627$

13) Jaïs P, Maury P, Khairy P, Sacher F, Nault I, Komatsu Y, Hocini M, Forclaz A, Jadidi AS, Weerasooryia R, Shah A, Derval N, Cochet H, Knecht S, Miyazaki S, Linton N, Rivard L, Wright M, Wilton SB, Scherr D, Pascale P, Roten L, Pederson M, Bordachar P, Laurent F, Kim SJ, Ritter P, Clementy J, Haïssaguerre M : Elimination of local abnormal ventricular activities : a new end point for substrate modification in patients with scar-related ventricular tachycardia. Circulation, $2012 ; 125: 2184 \sim 2196$

14) Reddy VY, Reynolds MR, Neuzil P, Richardson AW, Taborsky M, Jongnarangsin K, Kralovec S, Sediva L, Ruskin JN, Josephson ME : Prophylactic catheter ablation for the prevention of defibrillator therapy. $\mathrm{N}$ Engl J Med, 2007 ; 357 : 2657 ～ 6526

15) Kuck KH, Schaumann A, Eckardt L, Willems S, Ventura R, Delacrétaz E, Pitschner HF, Kautzner J, Schumacher B, Hansen PS ; VTACH study group : Catheter ablation of stable ventricular tachycardia before defibrillator implantation in patients with coronary heart disease (VTACH) : a multicentre randomised controlled trial. Lancet, 2010 ; 375 : 31 40

16) Bai R, Biase LD, Shivkumar K, Mohanty P, Tung R, Santangeli P, Saenz LC, Vacca M, Verma A, Khaykin Y, Mohanty S, Burkhardt JD, Hongo R, Beheiry S, Russo AD, Casella M, Pelargonio M, Santarelli P, Sanchez J, Tondo C, Natale A : Ablation of Ventricular Arrhythmias in Arrhythmogenic Right Ventricular Dysplasia/Cardiomyopathy. Arrhythmia-Free Survival After Endo-Epicardial Substrate Based Mapping and Ablation. Circ Arrhythm Electrophysiol, 2011 ; 4 : $478 \sim 485$ 